\title{
Homologous and Heterologous Adaptation of Listeria spp. to Essential Oils of Condiment Plants
}

\author{
Jéssica M. P. Santos ${ }^{1}$, Michelle C. Gonçalves ${ }^{1}$, Heloisa A. Martins ${ }^{1}$, \\ Juliana J. Pinelli' ${ }^{1}$, Silas R. Isidoro' ${ }^{1}$, Roberta H. Piccoli1,2* \\ ${ }^{1}$ Food Microbiology Laboratory, Universidade Federal de Lavras, Lavras, Brazil \\ ${ }^{2}$ Food Science Department, Universidade Federal de Lavras, Lavras, Brazil \\ Email: *rhpiccoli@dca.ufla.br
}

How to cite this paper: Santos, J.M.P., Gonçalves, M.C., Martins, H.A., Pinelli, J.J., Isidoro, S.R. and Piccoli, R.H. (2018) Homologous and Heterologous Adaptation of Listeria spp. to Essential Oils of Condiment Plants. Advances in Microbiology, 8, 639-649.

https://doi.org/10.4236/aim.2018.88043

Received: June 15, 2018

Accepted: August 28, 2018

Published: August 31, 2018

Copyright (c) 2018 by authors and Scientific Research Publishing Inc. This work is licensed under the Creative Commons Attribution International License (CC BY 4.0).

http://creativecommons.org/licenses/by/4.0/

(c) (i) Open Access

\begin{abstract}
The homologous and heterologous adaptation capacity of $L$. monocytogenes and $L$. innocua were determined for thyme, oregano and nutmeg essential oils, as well as their adaptation capacities to acidic stress. Minimum bactericidal concentrations (CMB) and minimum inhibitory and minimum growth $\mathrm{pH}$, were established. The capacity for increased tolerance to essential oils and acidic stress, along with heterologous adaptation among the essential oils tested and to acidic $\mathrm{pH}$ was determined, and that between $\mathrm{pH}$ and essential oils. L. monocytogenes and L. innocua adapted to all essential oils and to the minimum inhibitory $\mathrm{pH}$, after exposition to sub-lethal conditions. Both strains presented heterologous adaptation capacity. After previous exposition to sub-lethal essential oil concentrations, the regenerated cells were capable of growth under $3.5 \mathrm{pH}$ values, and increased $\mathrm{CMB}$ values. Essential oil CMBs for previously cultivated cells under minimum growth $\mathrm{pH}$ environments also increased, attaining values 1.6 times superior to previous ones.
\end{abstract}

\section{Keywords}

Cross-Adaptation, Natural Antimicrobial, L. monocytogenes, Tolerance

\section{Introduction}

The Listeria genus is comprised by various species, of which $L$. monocytogenes is greatly relevant due to the number of diseases it can cause to humans and other animals. L. innocua, for other hand, is not pathogenic, but it presents ecological, biochemical and genetic similarity with $L$. monocytogenes, which 
serves as response when exposed to the same physiochemical treatments. They are capable of surviving under hostile environmental conditions, such as refrigeration temperatures, acidic $\mathrm{pH}$ environments and high concentrations of sodium chloride. It therefore has the ability to break through food security and preservation barriers, making it a relevant food pathogen [1].

Microbial cells' capacity to adapt to inhospif environmental conditions is well documented. Such physiological responses to stress are directly related to survival and growth strategies. Some of the most important adaptation responses are sensing mechanisms, regulatory protein expression (for instance, RpoS), homeostatic system and repair induction, synthesis of shock response proteins and modification of cell membranes, particularly that of their fatty acids and their physical properties [2]. Microbial cells also have the capacity to develop cross-adaptation. This form of adaptation can occur when different antimicrobial agents act on the same target in the cell, following a common route to their respective targets, or establish a common path to cell death [3].

The capacity of $L$. monocytogenes to adapt to stressful conditions, its persistence in processing environments and its resistance to antimicrobial agents has become worrying. When exposed to acidic stress, L. monocytogenes cells alter the fluidity of their cytoplasmic membrane, incorporating linear chain fatty acids and reducing ramified chain fatty acids [4] [5]. Stress tolerance in L. monocytogenes is partially explained by the induction of gene transcription that participates in homeostatic functions and provides protection against stress conditions [6].

Use of essential oils has been suggested as a way to reduce these adaptation and cross-adaptation mechanisms due to these oils' complexity, which assures that they act upon various targets within microbial cells because the essential oils can alter the permeability of microbial cells, damage cytoplasmic membranes, change membrane proteins, interfere with the generation system of energy (adenosine triphosphate (ATP)) and disrupts a cell homeostasis, resulting in cell death [7]. In addition to essential oils' high antimicrobial activity, it has been reported that important bacteria in the food industry do not present significant changes to their sensibility to other antimicrobial substances, physical processes or stress factors after having been exposed to sub-lethal concentrations of essential oils, or to their major components [8] [9].

Some accounts of adaptation and cross-adaptation capacities to essential oils and their major components can be found in the literature. Such accounts have scrutinized adaptation and/or cross-adaptation capacities of L. monocytogenes ATCC 19117 to carvacrol and eugenol [10], of Salmonella senftenberg to linalol and to basil oil [11], $S$. enteritidis ATCC 13076, S. typhimurium ATCC 13311, Escherichia coli ATCC 25922 and Staphylococcus aureus ATCC 29213 to Origanum vulgare, Melaleuca alternifolia, Cinnamomum cassia and Thymus vulgaris [12] and of Staphylococcus aureus (in two of the four strains tested) to carvacrol [13]. However, no studies have been carried out showing the ability or not 
of bacteria, especially Listeria, to develop adaptation between essential oils and acid stress. The goal of the present article is, therefore, to evaluate the capacity of $L$. monocytogenes and L. innocua to adapt to thyme, oregano and nutmeg essential oils, and to acidic stress, as well as their capacity for cross-adaptation among these essential oils and to acidic stress, when exposed to sub-lethal concentrations of essential oils and acidic stress.

\section{Methods and Materials}

\subsection{Essential Oils}

Nutmeg, oregano and thyme essential oils were acquired from FERQUIMA Indústria e Comércio Ltda (Brazil). Their composition is shown in Table 1.

\subsection{Microorganisms and Cultivation Conditions}

The strains employed were L. monocytogenes ATCC19117 sertype $4 \mathrm{~d}$ and Listeria innocua ATCC 33090. Inoculum standardization (approximately $10^{8} \mathrm{CFU} / \mathrm{mL}$ ) was accomplished with a growth curve. Optic density $\left(\mathrm{OD}_{600 \mathrm{~nm}}\right)$ was monitored along with plate counting, on trypticase soy agar (TSA) plus $0.5 \%(\mathrm{~m} / \mathrm{v})$ yeast extract.

\subsection{Minimum Bactericidal Concentration of Essential Oils against Listeria spp.}

The essential oils' minimum bactericidal concentration (CMB) was obtained with microdilution in adapted polystyrene microplates with 96 cavities [14]. Essential oil solutions were prepared in trypticase soy broth (TSB) plus yeast extract (TSB-YE) with a $0.5 \%$ Tween 80 addition. Analyses were done at concentrations of $4 \% ; 2 \% ; 1 \% ; 0.5 \% ; 0.2 \% ; 0.1 \%$ and $0.05 \%(\mathrm{v} / \mathrm{v}) .150 \mu \mathrm{L}$ aliquots of the solutions were added to the cavities and $10 \mu \mathrm{L}$ of the standardized cultures were inoculated and incubated at $37^{\circ} \mathrm{C}$ for 24 hours. After incubation, aliquots of the

Table 1. Essential oil composition.

\begin{tabular}{ccc}
\hline Essential oils & Major components & Concentration (\%) \\
\hline Oregano $^{*}$ & Carvacrol & 73.11 \\
& E-Cariofileno & 4.32 \\
& $\gamma$-Terpineno & 3.93 \\
Thyme $^{*}$ & Timol & 2.97 \\
& Timol & 50.89 \\
Nutmeg & p-cinemo & 24.97 \\
& Alpha-pineno & 20 \\
& Beta-pineno & 14 \\
& Sabineno & 17 \\
\end{tabular}

${ }^{*}$ According to Souza et al. (2016); ${ }^{*}$ As provided by the company. 
cultures were plated in TSA-YE and incubated at $37^{\circ} \mathrm{C}$ for 24 hours.

A negative control was made with TSB-YE and $0.5 \%$ Tween 80 addition along with essential oils. The concentration of the essential oil solution in which growth was not observed was considered the CMB. The experiment was run in triplicate, with three repetitions.

\subsection{Minimum Growth $\mathrm{pH}$ and Minimum Inhibitory $\mathrm{pH}$ of Listeria spp.}

Minimum growth and minimum inhibitory $\mathrm{pH}$ of L. innocua and L. monocytogenes were determined with polystyrene microplates with 96 cavities. $150 \mu \mathrm{L}$ of TSB-YE were dispensed into each cavity, with $\mathrm{pH}$ values adjusted at $6.0 ; 5.5 ; 5.0$; $4.5 ; 4.0 ; 3.5 ; 3.0$ and 2.5 with lactic acid (98\%) along with $10 \mu \mathrm{l}$ of standardized cultures and microplates were incubated at $37^{\circ} \mathrm{C}$ for 24 hours and then plated in TSA-YE. Minimum inhibitory $\mathrm{pH}$ was defined through visual evaluation as the smallest value capable of completely inhibiting bacterial growth, while the minimum growth $\mathrm{pH}$ was defined as that immediately above the minimum inhibitory $\mathrm{pH}$. The experiment was run in triplicate, with three repetitions.

\subsection{Listeria spp. Adaptation to Sub-Lethal Conditions: Essential Oils and Acidic pH}

L. monocytogenes and L. innocua were adapted through cultivation under sub-lethal concentrations. Sublethal concentrations were determined by CMB divided by 4 and by $8(\mathrm{CMB} / 4$ and $\mathrm{CMB} / 8)$ of thyme, oregano and nutmeg essential oils in Falcon tubes containing $36 \mathrm{~mL}$ of TSB-YE with $0.5 \%$ Tween 80 added. $4 \mathrm{~mL}$ of the standardized culture were then added, and the tubes were subsequently placed under incubation at $37^{\circ} \mathrm{C}$ for 6 hours. L. innocua and $L$. monocytogenes cultivation under acidic $\mathrm{pH}$ was done in Falcon tubes containing TSB-YE, $\mathrm{pH} 4.5$, adjusted with lactic acid (98\%), at $37^{\circ} \mathrm{C}$ for $6 \mathrm{~h}$.

After incubation, the cultures were centrifuged $(5.000 \times \mathrm{g} / 5 \mathrm{~min})$, the supernatant was discarded and the pellets were sanitized three times with saline solution $(0.85 \% \mathrm{~m} / \mathrm{v})$. The pellets were again suspended in TSB-YE at around $10^{8} \mathrm{CFU} / \mathrm{mL}$. The experiment was run in triplicate, with three repetitions.

\subsection{Homologous Adaptation of Listeria spp. to Essential Oils and to Acidic pH}

The analysis of Listeria spp. adaptation to essential oils relied on suspensions of adapted standardized cells. $10 \mu \mathrm{L}$ aliquots of the suspension were inoculated into $150 \mu \mathrm{L}$ of essential oil solutions - the same oils to which cells had previously adapted-and incubated at $37^{\circ} \mathrm{C}$ for 24 hours. Solutions of each essential oil were prepared at concentrations of $0.5 \mathrm{CMB}$; $\mathrm{CMB} ; 1.2 \mathrm{CMB} ; 1.4 \mathrm{CMB} ; 1.6$ CMB; $1.8 \mathrm{CMB}$ and $2 \mathrm{CMB}$ in TSB-YE with a $0.5 \%$ Tween 80 addition. After incubation, $10 \mu \mathrm{L}$ aliquots of the cultures were plated in TSA-YE and incubated at $37^{\circ} \mathrm{C}$ for 24 hours. L. monocytogenes and L. innocua cells were found to be capable of developing homologous adaptation if they continued plated growth af- 
ter cultivation under concentrations equal or superior to CMB.

Tolerance to acidic stress was evaluated via inoculation of $10 \mu \mathrm{L}$ aliquots of the standardized suspension of cells that had been adapted to the minimum growth $\mathrm{pH}$ (4.5) into $150 \mu \mathrm{L}$ of TSB-YE under different $\mathrm{pH}$ values, adjusted with lactic acid (98\%). $\mathrm{pH}$ values of $6.0 ; 5.5 ; 5.0 ; 4.5 ; 4.0 ; 3.5$ and 2.5 were evaluated. Plates were incubated at $37^{\circ} \mathrm{C}$, for 24 hours. Subsequently, cultures were plated in TSA and incubated at $37^{\circ} \mathrm{C}$, for 24 hours. L. innocua and L. monocytogenes cells that grew in plating after cultivation under $\mathrm{pH}$ values inferior to minimum growth $\mathrm{pH}$ were considered capable of developing tolerance to acidic stress. Non-adapted cells were used as control.

\subsection{Evaluation of Heterologous Adaptation among Essential Oils and among Essential Oils and Acidic pH}

$10 \mu \mathrm{L}$ aliquots of the standardized $L$. innocua and $L$. monocytogenes cell solution that was adapted to $1 / 8$ essential oil $\mathrm{CMB}$ for 6 hours were inoculated into $150 \mu \mathrm{L}$ of the other essential oils. 0.5 CMB, CMB, 1.2 CMB, 1.4 CMB, 1.6 CMB, $1.8 \mathrm{CMB}$ and $2 \mathrm{CMB}$ concentrations were tested.

$10 \mu \mathrm{L}$ aliquots of the standardized cell suspension adapted to $1 / 8$ essential oil $\mathrm{CMB}$ were inoculated into $150 \mu \mathrm{L}$ TSB-YE with $\mathrm{pH}$ adjusted to 6.0 ; 5.5; 5.0 ; 4.5; $4.0 ; 3.5 ; 3.0$ and 2.5 with lactic acid (98\%), and incubated at $37^{\circ} \mathrm{C}$ for 24 hours. Subsequently, the cultures were plated in TSA-YE. L. innocua and L. monocytogenes heterologous adaptation capacity was determined by analyzing plated growth after exposition to $\mathrm{pH}$ values inferior to minimum growth $\mathrm{pH}$.

\subsection{Evaluation of Heterologous Adaptation between Acidic Stress and Essential Oils}

$10 \mu \mathrm{L}$ aliquots of the standardized cell suspension adapted to $4.5 \mathrm{pH}$ were inoculated into $150 \mu \mathrm{L}$ essential oil solutions under concentrations of $0.5 \mathrm{CMB}$; 1.2 CMB; $1.4 \mathrm{CMB}$; 1.6 CMB; 1.8 CMB and 2 CMB. The solutions were then incubated at $37^{\circ} \mathrm{C}$, for 24 hours. L. innocua and L. monocytogenes cultures that exhibited plated growth under essential oil concentrations equal or superior to CMB were considered capable of developing heterologous adaptation.

\section{Results}

Listeria innocua and L. monocytogenes presented the same behavior in all experiments. Essential oil CMB was $0.1 \%$ for thyme and oregano, and $0.2 \%$ for nutmeg. Minimum inhibitory $\mathrm{pH}$ and minimum growth $\mathrm{pH}$ were 4.0 and 4.5 , respectively.

The two strains were capable of developing homologous adaptation to essential oils. After exposition for $6 \mathrm{~h}$ to sublethal concentrations of $1 / 8 \mathrm{CMB}$ of oregano $(0.0125 \%)$, thyme $(0.0125 \%)$ and nutmeg $(0.025 \%)$ essential oils, they were able to grow under higher oil concentrations than the CMB. The new bactericidal concentration for cells adapted to oregano and thyme essential oils was $0.2 \%$ (2 $\mathrm{CMB})$, while for those adapted to nutmeg oil the new concentration was im- 
possible to obtain, as both $L$. innocua and $L$. monocytogenes were capable of growth under all concentrations tested (up to $2 \mathrm{CMB}$, or $0.4 \%$ ).

Cells adapted to sub-lethal concentrations of $1 / 4 \mathrm{CMB}(0.025 \%$ oregano and thyme; $0.05 \%$ nutmeg) were found to have a new $\mathrm{CMB}$ of $0.16 \%$ (1.6 CMB) for oregano and thyme essential oils, and $0.4 \%$ (2 CMB) for nutmeg oil.

Homologous adaptation to acidic stress was also observed. Minimum inhibitory $\mathrm{pH}$, previously 4.0 , decreased to 3.5 for both strains.

Both $L$. innocua and $L$. monocytogenes developed the some heterologous adaptations among essential oils (Table 2).

Both L. innocua and L. monocytogenes showed heterologous adaptation capacity to acidic stress. After being exposed to sub-lethal concentrations (1/8 CMB) of thyme and oregano essential oils $(0.0125 \%)$ and nutmeg $(0.025 \%)$, the strains were capable of growth in environments of $\mathrm{pH} 4.0$, a lower value to that of the previously established minimum growth $\mathrm{pH}$ (4.5). The new minimum inhibitory $\mathrm{pH}$ was 3.5.

After adaptation to the minimum growth $\mathrm{pH}(\mathrm{pH} 4.5), L$. innocua and $L$. monocytogenes developed heterologous adaptation to thyme, oregano and nutmeg essential oils. The strains were capable of growth when plated with 1.4 times the $\mathrm{CMB}$ of each oil. The new CMB for both strains were $0.16 \%$ (1.6 CMB) for oregano and thyme essential oils, and $0.32 \%(1.6 \mathrm{CMB})$ for nutmeg oil.

\section{Discussion}

Nutmeg oil was determined to have had twice as high a CMB (0.2\%) than its thyme and oregano counterparts (0.1\%). Against L. monocytogenes, specifically, the literature has suggested that oregano essential oil CMB may vary between $0.005 \%$ and $0.6 \%$, depending on strain and methodology [15]. The same observation may be made for thyme oil, which has been shown to wield various CMB values-0.1\% [16], 0.2\% [17], 0.39\% [18] and 0.5\% [19]. Minimum inhibitory concentration for nutmeg oil against $L$. monocytogenes was determined to be $0.2 \%$ [20], the same value found by this work.

Essential oils' antimicrobial activity is attributed mainly to their major compounds, although their trace components may contribute significantly to their

Table 2. Heterologous adaptation of Listeria monocytogenes and Listeria innocua to thyme, oregano and nutmeg essential oils.

\begin{tabular}{cccc}
\hline Stress sublethal & Conc. Sublethal (\%) & Stress lethal & Lethal Conc. (\%) \\
\hline Thyme & $0.0125^{\star}$ & Oregano & $0.18^{\star}$ \\
& 0.0125 & Nutmeg & 0.36 \\
Oregano & $0.0125^{\star}$ & Thyme & $0.18^{\star}$ \\
& 0.0125 & Nutmeg & 0.36 \\
Nutmeg & $0.025^{*}$ & Thyme & $0.18^{\star}$ \\
& 0.025 & Oregano & 0.18 \\
\hline
\end{tabular}

* Listeria monocytogenes, Listeria innocua. 
effectiveness. Oregano, thyme and nutmeg essential oils are known antimicrobial compounds. Their antibacterial is associated with its phenolic major compounds, carvacrol, thymol, $\alpha$-pinene and $\beta$-pinene [7]. Although these components present known antimicrobial activity, their biological activity is dependent on their chemical structure. Carvacrol, for instance, is twice as potent as $\alpha$-pinene and $\beta$-pinene against gram positive bacteria [21]. The sum of $\alpha$ and $\beta$-pinene present in nutmeg oil amounted to $34 \%$ of its composition, while carvacrol and thimol in oregano, and thimol in thyme, $76.08 \%$ and $50.89 \%$ respectively. It may be said that the results of this work reflect the antimicrobial action of the major compounds of the essential oils studied.

Bacterial capacity for homologous and heterologous adaptation to transient conditions is well known, particularly with regards to oxidation, acidic conditions, thermal stress, high pressures, antibiotics and sanitizing agents. However, little is known about food-borne bacteria's capacity for adaptation to essential oils. In this work, both Listeria strains analyzed developed homologous as well as heterologous adaptation to these oils.

Adaptation mechanisms to essential oils and their major compounds are not yet well known, and there are few works published in the literature. Salmonella thompson exposition to sub-lethal doses of thymol has, however, been studied, leading to observations of protein synthesis associated with stress and damage to cellular metabolism [22]. Bacillus cereus cultivated under sub-lethal carvacrol concentrations has also been shown to present reductions to the fluidity of cells cytoplasmic membrane, and alterations to their fatty acid make-up [23]. However, transcriptomic analyses show that $L$. monocytogenes response to sub-lethal stress caused by essential oils is complex [24].

Comparative transcriptomic analysis of $L$. monocytogenes serotype $4 \mathrm{~b}$ adapted to sub-lethal concentrations of Baccharis psiadioides essential oil showed various changes to the regulation of genes associated to stress response and a decrease in gene expression associated to virulence factors [24]. Different $L$. monocytogenes isolates, after exposition to sub-lethal doses of lemongrass essential oil led to modifications to the expression of genes associated with fatty acid and peptideoglycan bio-synthesis, as well as to key genes associated with virulence factors [25].

Proteomic analyses also show that bacteria exposed to sub-lethal concentrations of essential oils or to their major compounds promote changes to the profiles of proteins associated to fatty acid bio-synthesis. This was shown for E. coli, L. monocytogenes and $S$. enteritidis that had their protein profiles altered, increasing unsaturated fatty acid concentrations after exposition to sub-lethal doses of thyme and oregano essential oils, as well as to carvacrol, thymol, trans-2-hexenal and citral [26]. This change to fatty acid composition may contribute to the understanding of stress response mechanisms employed by different pathogenic microorganisms responsible for food-borne disease, including with regards to exposition to sub-lethal concentrations of natural antimicrobial 
substances.

Weak acids affect cellular capacity to maintain $\mathrm{pH}$ homeostasis, interrupting substrate transportation and inhibiting metabolic pathways [27]. However, it is known that $L$. monocytogenes is capable of developing tolerance to acidic $\mathrm{pH}$ values, growing even in $3.5 \mathrm{pH}$ environments [4], in line with the findings of the present work.

Heterologous adaptation was found, in this study, to be similar for both strains. This may have occurred due to the concurrent action of the essential oils and lactic acid over similar targets within the cell, namely, over common physiological mechanisms that lead to cell death, or due to common access pathways to their respective targets [3]. Juven et al. [28] state that the antibacterial properties of some essential oil components may be improved after exposition to low $\mathrm{pH}$ values. However, in this study, this behavior was not observed. Both strains exposed to $4.5 \mathrm{pH}$ (minimum growth $\mathrm{pH}$ ) presented higher tolerance to essential oils. Based on the concept of heterologous adaptation, cross-tolerance development was observed for both $L$. innocua and L. monocytogenes when previously exposed to sub-lethal $\mathrm{pH}$ and essential oil-rich environments.

The Sigma B alternative factor is a protein responsible for controlling important genes that regulate stress response, virulence, transcriptional regulation, carbohydrate metabolism and transportation. It affects mobility and chemotaxis in both L. innocua and L. monocytogenes. The regulation of both strains by alternative factor Sigma B show a common cluster of at least 49 genes [29] that may also be related to the similar behavior exhibited by these strains in this study.

Information regarding bacterial adaptational responses to sub-lethal conditions is important for food microbiology, seeing as many processes to which bacteria are submitted during processing are of non-lethal character, which represents risks to sanitation and consumer health.

\section{Conclusion}

Listeria innocua and L. monocytogenes both presented adaptational capacity when exposed to sub-lethal essential oil concentrations and to minimum growth $\mathrm{pH}$. Both species developed heterologous adaptation among essential oils and to acidic stress, and between acidic stress and essential oil treatment. The ability of the strains to develop heterologous adaptation is extremely worrying, being a cause for alert for the use of essential oils in food in sublethal concentrations.

\section{Conflicts of Interest}

The authors declare that they have no conflict of interest.

\section{References}

[1] Buchanan, R.L., Gorris, L.G.M., Hayman, M.M., Jackson, T.C. and Whiting, R.C. (2017) A Review of Listeria monocytogenes: An Update on Outbreaks, Virulence, 
Dose-Response, Ecology, and Risk Assessments. Food Control, 75, 1-13. https://doi.org/10.1016/j.foodcont.2016.12.016

[2] Alvarez-Ordóñez, A., Broussolle, V., Colin, P., Nguyen, C. and Prieto, M. (2015) The Adaptive Response of Bacterial Food-Borne Pathogens in the Environment, Host and Food: Implications for Food Safety. International Journal of Food Microbiology, 213, 99-109. https://doi.org/10.1016/j.ijfoodmicro.2015.06.004

[3] Chapman, J.S. (2003) Disinfectant Resistance Mechanisms, Cross-Resistance, and Co-Resistance. International Biodeterioration \& Biodegradation, 51, 271-276. https://doi.org/10.1016/S0964-8305(03)00044-1

[4] Badaoui-Najjar, M.Z., Chikindas, M.L. and Montville, T.J. (2009) The Acid Tolerance Response Alters Membrane Fluidity and Induces Nisin Resistance in Listeria monocytogenes. Probiotics and Antimicrobial Proteins, 1, 130-135.

https://doi.org/10.1007/s12602-009-9025-8

[5] Mastronicolis, S.K., Berberi, A., Diakogiannis, I., Petrova, E., Kiaki, I. and Baltzi, T. (2010) Alteration of the Phospho- or Neutral Lipid Content and Fatty Acid Composition in Listeria monocytogenes Due to Acid Adaptation Mechanisms for Hydrochloric, Acetic and Lactic Acids at pH 5.5 or Benzoic Acid at Neutral pH. Antonie van Leeuwenhoek, 98, 307-316. https://doi.org/10.1007/s10482-010-9439-z

[6] Gahan, C.G.M. and Hill, C (2014) Listeria monocytogenes: Survival and Adaptation in the Gastrointestinal Tract. Frontiers in Cellular and Infection Microbiology, 4, 9. https://doi.org/10.3389/fcimb.2014.00009

[7] Nazzaro, F., Fratianni, F., Martino, L., Coppola, R. and De Feo, V. (2013) Effect of Essential Oils on Pathogenic Bacteria. Pharmaceuticals, 6, 1451-1474.

https://doi.org/10.3390/ph6121451

[8] Gomes Neto, N.J., Luz, I.S., Honório, W.G., Tavares, A.G. and Souza, E.L. (2012) Rosmarinus officinalis L. Essential Oil and the Related Compound 1,8-Cineole Do Not Induce Direct or Cross-Protection in Listeria monocytogenes ATCC 7644 Cultivated in Meat Broth. Canadian Journal of Microbiology, 58, 973-981. https://doi.org/10.1139/w2012-070

[9] Souza, E.L. (2016) The Effects of Sublethal Doses of Essential Oils and Their Constituents on Antimicrobial Susceptibility and Antibiotic Resistance among Food-Related Bacteria: A Review. Trends in Food Science \& Technology, 56, 1-12. https://doi.org/10.1016/j.tifs.2016.07.012

[10] Souza, E.R.N., Tebaldi, V.M.R. and Piccoli, R.H. (2015) Adaptação e adaptação cruzada de Listeria monocytogenes aos compostos eugenol e carvacrol [Adaptation and Cross Adaptation of Listeria monocytogenes to Eugenol and Carvacrol Compounds]. Revista Brasileira de Plantas Medicinais, 17, 528-533. https://doi.org/10.1590/1983-084X/13_098

[11] Kalily, E., Hollander, A., Korin, B., Cymerman, I. and Yaron, S. (2017) Adaptation of Salmonella enterica Serovar Senftenberg to Linalool and Its Association with Antibiotic Resistance and Environmental Persistence. Applied and Environmental Microbiology, 83, 1-17. https://doi.org/10.1128/AEM.03398-16

[12] Melo, A.D.B., Amaral, A.F., Schaefer, G., Luciano, F.B., Andrade, C., Costa, L.B. and Rostagno, M.H. (2015) Antimicrobial Effect against Different Bacterial Strains and Bacterial Adaptation to Essential Oils Used as Feed Additives. Canadian Journal of Veterinary Research, 79, 285-289.

[13] Nostro, A., Marino, A., Ginestra, G., Cellini, L., Di Giulio, M. and Bisignano, G. (2017) Effects of Adaptation to Carvacrol on Staphylococcus aureus in the Planktonic and Biofilm Phases. Biofouling, 33, 470-480. 
https://doi.org/10.1080/08927014.2017.1323080

[14] Oliveira, M.M.M., Brugnera, D.F. and Piccoli, R.H. (2013) Essential Oils of Thyme and Rosemary in the Control of Listeria monocytogenes in Raw Beef. Brazilian Journal of Microbiology, 44, 1181-1188. https://doi.org/10.1590/S1517-83822013000400022

[15] Sakkas, H. and Papadopoulou, C. (2017) Antimicrobial Activity of Basil, Oregano, and Thyme Essential Oils. Journal of Microbiology and Biotechnology, 27, 429-438. https://doi.org/10.4014/jmb.1608.08024

[16] Oussalah, M., Caillet, S., Saucier, L. and Lacroix, M. (2007) Inhibitory Effects of Selected Plant Essential Oils on the Growth of Four Pathogenic Bacteria: E. coli O157:H7, Salmonella Typhimurium, Staphylococcus aureus and Listeria monocytogenes. Food Control, 18, 414-420. https://doi.org/10.1016/j.foodcont.2005.11.009

[17] García-Díez, J., Alheiro, J., Pinto, A.L., Soares, L., Falco, V., Fraqueza, M.J. and Patarata, L. (2017) Influence of Food Characteristics and Food Additives on the Antimicrobial Effect of Garlic and Oregano Essential Oils. Foods, 6, 44. https://doi.org/10.3390/foods6060044

[18] Gouveia, A.R., Alves, M., Silva, J.A. and Saraiva, C. (2016) The Antimicrobial Effect of Rosemary and Thyme Essential Oils against Listeria monocytogenes in Sous Vide Cook-Chill Beef during Storage. Procedia Food Science, 7, 173-176. https://doi.org/10.1016/j.profoo.2016.10.001

[19] Millezi, A.F., Caixeta, D.S., Rossoni, D.F., Cardoso, M.M. and Piccoli, R.H. (2012) In Vitro Antimicrobial Properties of Plant Essential Oils Thymus vulgaris, Cymbopogon citratus and Laurus nobilis against Five Important Foodborne Pathogens. Ciência e Tecnologia de Alimentos, 32, 167-172. https://doi.org/10.1590/S0101-20612012005000021

[20] Firouzi, R., Shekarforoush, S.S., Nazer, A.H.K., Borumand, Z. and Jooyandeh, A.R. (2007) Effects of Essential Oils of Oregano and Nutmeg on Growth and Survival of Yersinia enterocolitica and Listeria monocytogenes in Barbecued Chicken. Journal of Food Protection, 70, 2626-2630. https://doi.org/10.4315/0362-028X-70.11.2626

[21] Leite, A.M., Lima, E.O., Souza, E.L., Diniz, M.F.F.M., Trajano, V.N. and Medeiros, I.A. (2007) Inhibitory Effect of Beta-Pinene, Alpha-Pinene and Eugenol on the Growth of Potential Infectious Endocarditis Causing Gram-Positive Bacteria. Revista Brasileira de Ciências Farmacêuticas, 43, 121-126. https://doi.org/10.1590/S1516-93322007000100015

[22] Di Pasqua, R., Mamone, G., Ferranti, P., Ercolini, D. and Mauriello, G. (2010) Changes in the Proteome of Salmonella enterica Serovar Thompson as Stress Adaptation to Sublethal Concentrations of Thymol. Proteomics, 10, 1040-1049.

[23] Ultee, A., Kets, E.P.W., Alberda, M., Hoekstra, F.A. and Smid, E.J. (2000) Adaptation of the Food-Borne Pathogen Bacillus cereus to Carvacrol. Archives of Microbiology, 174, 233-238. https://doi.org/10.1007/s002030000199

[24] Pieta, L., Escudero, F.L.G, Jacobus, A.P., Cheiran, K.P., Gross, J. and Moya, M.L.E. (2017) Comparative Transcriptomic Analysis of Listeria monocytogenes Reveals Upregulation of Stress Genes and Downregulation of Virulence Genes in Response to Essential Oil Extracted from Baccharis psiadioides. Annals of Microbiology, 67, 479-490. https://doi.org/10.1007/s13213-017-1277-z

[25] Hadjilouka, A., Mavrogiannis, G., Mallouchos, A., Paramithiotis, S., Mataragas, M. and Drosinos, E.H. (2017) Effect of Lemongrass Essential Oil on Listeria monocytogenes Gene Expression. LWT-Food Science and Technology, 77, 510-516. https://doi.org/10.1016/j.lwt.2016.11.080 
[26] Siroli, L., Patrignani, F., Gardini, F. and Lanciotti, R. (2015) Effects of Sub-Lethal Concentrations of Thyme and Oregano Essential Oils, Carvacrol, Thymol, Citral and Trans-2-Hexenal on Membrane Fatty Acid Composition and Volatile Molecule Profile of Listeria monocytogenes, Escherichia coli and Salmonella Enteritidis. Food Chemistry, 182, 185-192. https://doi.org/10.1016/j.foodchem.2015.02.136

[27] Beales, N. (2004) Adaptation of Microorganisms to Cold Temperatures, Weak Acid Preservatives, Low $\mathrm{pH}$, and Osmotic Stress: A Review. Comprehensive Reviews in Food Science and Food Safety, 3, 1-20.

https://doi.org/10.1111/j.1541-4337.2004.tb00057.x

[28] Juven, B.J., Kanner, J., Schved, F. and Weisslowicz, H. (1994) Factors That Interact with the Antibacterial Action of Thyme Essential Oil and Its Active Constituents. Journal of Applied Bacteriology, 76, 626-631. https://doi.org/10.1111/j.1365-2672.1994.tb01661.x

[29] Raengpradub, S., Wiedmann, M. and Boor, K.J. (2008) Comparative Analysis of the b-Dependent Stress Responses in Listeria monocytogenes and Listeria innocua Strains Exposed to Selected Stress Conditions. Applied and Environmental Microbiology, 74, 158-171. https://doi.org/10.1128/AEM.00951-07 